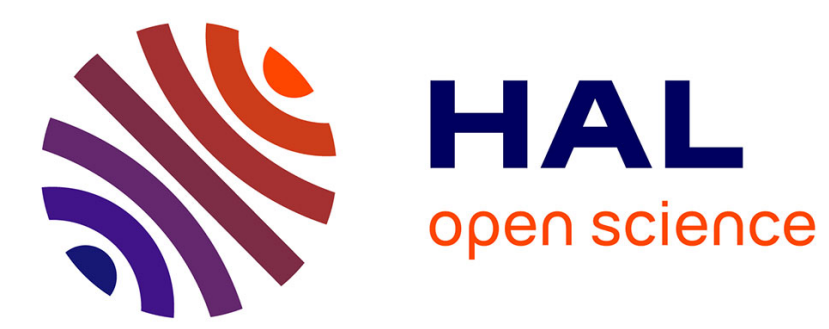

\title{
Free Radical Emulsion Polymerization of Ethylene
}

Guilhem Billuart, Elodie Bourgeat-Lami, Muriel Lansalot, Vincent Monteil

\section{To cite this version:}

Guilhem Billuart, Elodie Bourgeat-Lami, Muriel Lansalot, Vincent Monteil. Free Radical Emulsion Polymerization of Ethylene. Macromolecules, 2014, 47 (19), pp.6591 - 6600. 10.1021/ma5012733. hal-01859690

\section{HAL Id: hal-01859690 \\ https://hal.science/hal-01859690}

Submitted on 22 Dec 2021

HAL is a multi-disciplinary open access archive for the deposit and dissemination of scientific research documents, whether they are published or not. The documents may come from teaching and research institutions in France or abroad, or from public or private research centers.
L'archive ouverte pluridisciplinaire HAL, est destinée au dépôt et à la diffusion de documents scientifiques de niveau recherche, publiés ou non, émanant des établissements d'enseignement et de recherche français ou étrangers, des laboratoires publics ou privés. 


\section{Submitted to Macromolecules}

This document is confidential and is proprietary to the American Chemical Society and its authors. Do not copy or disclose without written permission. If you have received this item in error, notify the sender and delete all copies.

\section{Free radical emulsion polymerization of ethylene}

\begin{tabular}{|r|l|}
\hline Journal: & Macromolecules \\
\hline Manuscript ID: & ma-2014-012733.R1 \\
\hline Manuscript Type: & Article \\
\hline Date Submitted by the Author: & 19 -Sep-2014 \\
\hline Complete List of Authors: & $\begin{array}{l}\text { BILLUART, Guilhem; UMR 5265, Chimie Catalyse Polymères et Procédés } \\
\text { (C2P2) } \\
\text { Bourgeat-Lami, Elodie; Laboratoire de Chimie et Procédés de } \\
\text { Polymérisation, LCPP - CNRS - CPE } \\
\text { Lansalot, Muriel; UMR 5265, Chimie Catalyse Polymères et Procédés } \\
\text { (C2P2) } \\
\text { Monteil, Vincent; Université de Lyon / CNRS, Chimie }\end{array}$ \\
\hline
\end{tabular}

SCHOLARONE

Manuscripts 


\title{
Free radical emulsion polymerization of ethylene
}

\author{
G. Billuart, E. Bourgeat-Lami, M. Lansalot, V. Monteil* \\ Université de Lyon, Univ. Lyon 1, CPE Lyon, CNRS, UMR 5265, Laboratoire de Chimie, \\ Catalyse, Polymères et Procédés (C2P2), LCPP group, 43, Bd. du 11 Novembre 1918, F-69616 \\ Villeurbanne, France
}

KEYWORDS. Ethylene, free radical, emulsion polymerization, nanoparticles, supercooling, film formation.

\begin{abstract}
Free radical polymerization of ethylene in aqueous media was performed under mild conditions ( $\mathrm{T}<90{ }^{\circ} \mathrm{C}$ and $\mathrm{P}_{\text {ethylene }}<250$ bar) using an anionic initiating (ammonium persulfate, APS) and stabilizing (sodium dodecyl sulfate, SDS) system, yielding polyethylene latexes. $\mathrm{pH}$ regulation was a key to the feasibility of this process. Particle sizes and morphologies as well as polymerization yields were affected by SDS concentration. In any case, yields increased with polymerization time, especially in presence of surfactant. When increasing the polymerization pressure, the increase on yields was much stronger in presence of surfactant and particle sizes increased more when no surfactant was used. Stable polyethylene latexes with relatively high
\end{abstract}


solids content $(30 \%)$ were synthesized. This article also reports a supercooling effect on the crystallization of the polyethylene particles and evidences promising water-repellency properties of paper coated with the PE latexes synthesized in our laboratory.

\section{Introduction}

Polyethylene (PE), the top manufactured polymer, can be synthesized by two different polymerization routes. The free radical way, discovered in the 1930 s by Imperial Chemical Industries (ICI), produces Low-Density PolyEthylene (LDPE). This synthesis requires very harsh polymerization conditions: high temperatures $\left(\mathrm{T} \approx 300{ }^{\circ} \mathrm{C}\right)$ and high pressures $\left(\mathrm{P}_{\text {Ethylene }}>2000\right.$ bar). ${ }^{1-3}$ The obtained polymer is highly branched, thus leading to a low density and low crystallinity material. The other route, a catalytic process discovered by Ziegler and Phillips Petroleum in the 1950s, yields High-Density PolyEthylene (HDPE): a very linear PE with very high crystallinity. By copolymerizing ethylene with $\alpha$-olefins such as 1-butene or 1-hexene, a slightly branched PE is obtained, named LLDPE for Linear Low-Density PolyEthylene. ${ }^{1,4}$ LLDPE exhibits an intermediate crystallinity between LDPE and HDPE.

Despite its hydrophobicity, PE is used by certain industries (e.g. inks, concrete, wood...) under the form of dispersions in water. To obtain such products, the aforementioned LDPE is poured into hot water, in presence of surfactants, and dispersed under the effect of a strong mechanical stirring, leading to $10 \mu \mathrm{m}$ wax particles. ${ }^{5,6}$ The dispersion is then submitted to a high pressure homogenization process to reach particle sizes around $2 \mu \mathrm{m}$. As one can imagine, this process involving several steps to obtain a PE dispersion is long, energy consuming and thus expensive.

In our laboratory, it has been shown lately that the production of PE via a free radical pathway can be efficient under much milder temperature and pressure conditions than the ones described 
above. Slurry polymerization was, at first, carried out in organic solvents using 2,2'azobisisobutyronitrile (AIBN) as organosoluble initiator. This polymerization process benefited from an important activation effect from the solvent. Indeed, polar organic solvents such as THF or dialkyl-carbonates greatly improved the polymerization yields. ${ }^{7}$ However, despite interesting yields, chain transfer reactions of the growing radical to the solvent produced low molar mass PEs, usually lower than $7000 \mathrm{~g} \mathrm{~mol}^{-1} .{ }^{8}$ To lower the extent of transfer reactions, ethylene polymerization was then studied in water, a polar, non-transferring solvent. ${ }^{9}$

A cationic, hydrosoluble equivalent of AIBN, 2,2'-azobis(2-methylpropionamide) dihydrochloride (AIBA), was used to initiate the reaction. Stable latexes of low solids content (1 to $4 \%$ ), containing spherical PE nanoparticles (average hydrodynamic particle diameters: $60-100$ $\mathrm{nm}$ ), were obtained yielding dispersions of PE nanoparticles in a one-step synthesis. The PE particles were assumed to be stabilized by positively charged initiator fragments located at chain ends. In presence of a cationic surfactant, cetyl trimethyl ammonium bromide (CTAB), the obtained latexes were still stable and produced with much higher yields (up to $30 \%$ of solids content) and high molar masses (typically larger than $50000 \mathrm{~g} \mathrm{~mol}^{-1}$ ). In this case, the PE nanoparticles were smaller $(20-50 \mathrm{~nm})$ and presented disc-like shapes, as evidenced by TEM analysis. These unusual particle morphologies were attributed to the crystallinity of the polymer which seems to prevent the formation of spherical objects in the presence of surfactant. Aqueous dispersions of semi-crystalline PE nanoparticles, obtained from aqueous catalytic processes, exhibiting such particle morphologies have already been reported. ${ }^{10-15}$ It is also important to keep in mind that free radical polymerization of ethylene in water was reported as early as in the 1940s but in these pioneering works no precise information on colloidal properties was given. ${ }^{16-20}$ 
On top of making the use of emulsion polymerization techniques for ethylene possible, the polymerization process in aqueous dispersed media also tackles the question of the locus of polymerization. Indeed, during a slurry free radical polymerization of ethylene (FRPE) in an organic solvent under medium pressure conditions, the polymerization medium can be monophasic (solvent and ethylene form a single phase) or biphasic, depending on both the experimental conditions and the solvent's supercritical properties. ${ }^{21}$ Emulsion polymerization benefits from the thermodynamic properties of water, i.e. a very high critical point $\left(347{ }^{\circ} \mathrm{C}, 221\right.$ bar) compared to organic solvents, preventing the formation of a supercritical monophasic medium: a liquid aqueous phase coexists with the supercritical ethylene phase. Consequently, as this polymerization process uses a hydrosoluble initiator, the polymerization will be initiated in the aqueous phase.

In line with our previous works, ${ }^{9}$ we wanted to explore the synthesis of negatively charged PE latexes through emulsion polymerization. Indeed, controlling the surface charge of the particles is important to expand the versatility of this process. Herein, we will therefore study the feasibility of the free radical emulsion polymerization of ethylene using a very conventional, anionic initiating and stabilizing system, commonly used in emulsion polymerization. The thermal properties of the resulting latexes will then be discussed. Finally, the water-repellency properties of paper coated with PE latexes will be evaluated. 


\section{Experimental.}

\section{Materials:}

Ethylene (99.95\%, Air Liquide), 2,2'-azobis(2-methylpropionamide) (AIBA, 98\% Acros Organics), 4,4'-azobis(4-cyanopentanoic acid) (ACPA, >98\% Fluka), ammonium persulfate (APS, 98\% Acros Organics), cetyl trimethyl ammonium bromide (CTAB, 99\% Sigma-Aldrich), sodium dodecyl sulfate (SDS, 99\% Acros Organics), sodium bicarbonate (99,7\%, SigmaAldrich), potassium carbonate (99\%, Sigma-Aldrich), sodium hydroxide ( $>98 \%$, Sigma-Aldrich), LDPE (Acros Organics) were used as received. Water was purified by an ELGA Labwater Classic: impurities were removed by ultrafiltration and UV irradiation.

\section{Characterizations:}

Latex colloidal properties:

Hydrodynamic particle diameters $\left(\mathrm{Z}_{\mathrm{av}}, \mathrm{nm}\right)$ were measured by a Malvern Zetasizer Nano ZS. A $633 \mathrm{~nm}$ wavelength laser beam was sent to an infinitely diluted sample and the scattered signal intensity analyzed at a $173^{\circ}$ angle, at $25^{\circ} \mathrm{C}$. Dynamic Light Scattering (DLS) allowed access to the particle sizes and the broadness of the size distribution (indicated by the poly value - the higher this value, the broader the size distribution) by computation using the cumulant analysis method. From DLS data, particle numbers were calculated using equation (1).

$$
\mathrm{N}_{\mathrm{p}}=6 \tau /\left(\pi Z_{a v} 10^{-21} \mathrm{dp}\right)(1)
$$

With $\mathrm{N}_{\mathrm{p}}$, the number of particles $\left(\mathrm{mL}^{-1}\right), \tau$ the polymer concentration $\left(\mathrm{g} \mathrm{mL}^{-1}\right), Z_{a v}$ the average particle size $(\mathrm{nm})$ and $\mathrm{d}_{\mathrm{p}}$ the polymer density $\left(\mathrm{g} \mathrm{cm}^{-3}\right)$. Here, $\mathrm{d}_{\mathrm{p}}$ was set to $0.86 \mathrm{~g} \mathrm{~cm}^{-3}$, the density of a very low density polyethylene (VLDPE). ${ }^{22}$ 
Cryo-TEM was performed at the CT $\mu$ (Centre Technologique des Microstructures - Plateform of the Université Claude Bernard Lyon 1, Villeurbanne, France) on a Philips CM120 transmission electron microscope. The sample was diluted until reaching a $1 \%$ solids content. A drop of the solution was placed on a Quantifoil R2/1 copper grid with 100 holey Carbon support film. The grid was then plunged into liquid ethane, leading to the formation of amorphous ice that will imprison the particles, preserving their morphology, as opposed to regular TEM analysis.

Initial and final $\mathrm{pH}$ values $\left(\mathrm{pH}_{\mathrm{i}}\right.$ and $\mathrm{pH}_{\mathrm{f}}$, respectively) of the aqueous phase were probed by a pH-meter (Seven Easy, Mettler Toledo) using a combined glass electrode (Mettler Toledo).

To remove the free surfactant from the latexes, dialyses were performed. A fraction of the latex was introduced in a dialysis tubing (molar mass cutoff $6000-8000 \mathrm{~g} \mathrm{~mol}^{-1}$ ), itself immerged in ultrapure water. The water was renewed every day for one week.

\section{Polymer characterizations:}

Polymer molar masses were measured by Size Exclusion Chromatography (SEC) using a Viscotek Malvern HT-GPC Module 350A equipped with three mixed bed columns $(300 \times 7.8 \mathrm{~mm}$ from Malvern Instrument) and a guard column $(75 \times 7.5 \mathrm{~mm})$. Dry polymer samples were dissolved at $150{ }^{\circ} \mathrm{C}$ in 1,2,4-trichlorobenzene (stabilized with 2,6-di(tert-butyl)-4-methylphenol), at a $3 \mathrm{mg} \mathrm{mL}^{-1}$ concentration. The determination of the molar masses was based on a triple detector set: viscometer, refractometer, light scattering at a low angle (LALS) and a right angle (RALS) under a $1 \mathrm{~mL} \min ^{-1}$ flow. This triple detection allows an absolute measurement of the polymer molar masses (number-average molar mass, $M_{\mathrm{n}}$ and weight-average molar mass, $M_{\mathrm{w}}$ ) and molar-mass dispersity $\left(~ Ð=M_{\mathrm{w}} / M_{\mathrm{n}}\right)$, without need for calibration standards. 
Branching degrees of the polymers were measured by ${ }^{13} \mathrm{C}$ NMR on a Bruker Avance II 400 Ascend in a tetrachloroethylene (TCE) / deuterated benzene mixture $(2 / 1 \mathrm{v} / \mathrm{v})$ in $10 \mathrm{~mm}$ tubes at $90{ }^{\circ} \mathrm{C}$ with a $10 \mathrm{~mm} \mathrm{SEX}-{ }^{13} \mathrm{C} /{ }^{1} \mathrm{H}$ probe at the NMR Polymer Center of Institut de Chimie de Lyon (FR5223) (Villeurbanne, France). Branching density calculations were performed according to the work of Galland et al. ${ }^{23}$

Differential Scanning Calorimetry (DSC) measurements were performed on a Mettler-Toledo DSC-1. The dried samples (bulk PE) were submitted to two successive heating (10 to $160{ }^{\circ} \mathrm{C}$ at 5 $\left.{ }^{\circ} \mathrm{C} \min ^{-1}\right)$ and cooling $\left(160\right.$ to $10{ }^{\circ} \mathrm{C}$ at $\left.-20{ }^{\circ} \mathrm{C} \min ^{-1}\right)$ cycles in a standard $40 \mu \mathrm{L}$ aluminum crucible, with an empty reference crucible. The analyzed data (melting temperature, $\mathrm{T}_{\mathrm{m}}$ and crystallinity, $\mathrm{X}_{\mathrm{C}}, \%$ ) are extracted from the second heating. Crystallinity was calculated with the following equation where $\Delta \mathrm{H}_{\mathrm{f}, \infty}$ is $293 \mathrm{~J} \mathrm{~g}^{-1}$.

$$
\mathrm{X}_{\mathrm{c}}=\left(\Delta \mathrm{H}_{\mathrm{f}, \text { measured }} / \Delta \mathrm{H}_{\mathrm{f}, \infty}\right) \times 100
$$

DSC was also performed directly on the PE particles dispersion. To this purpose the latexes were submitted to an analog cycle as for bulk PE, this time in a medium pressure $120 \mu \mathrm{L}$ stainless steel crucible sealed with a Viton O-ring, with temperatures ranging from 0 to $130{ }^{\circ} \mathrm{C}$ and heating or cooling rates of $5{ }^{\circ} \mathrm{C} \min ^{-1}$ or $-5{ }^{\circ} \mathrm{C} \min ^{-1}$. For each sample, the reference crucible was filled with an aqueous solution of surfactant, whose concentration was close to the one used to synthesize the sample. Crystallization temperature $\left(\mathrm{T}_{\mathrm{c}}\right)$ was extracted from the cooling segment, whereas $T_{m}$ was obtained from the second heating. A DLS analysis was performed on the latexes in order to check their colloidal stability after the DSC cycles. 


\section{Permeability measurements:}

Cobb test measurements were performed by submerging a known surface of coated paper in 1 $\mathrm{cm}$ of water (coated face up) during 1 minute. Surplus water was then removed by pressing a sheet of blotting paper on the wetted surface. By weighing the sample before and after wetting, the amount of absorbed water could be calculated in $\mathrm{g} \mathrm{m}^{-2}$.

Moisture Vapor Transmission Rate (MVTR) was determined by sealing a cup containing a dessicant salt (anhydrous $\mathrm{CaCl}$ ) with a piece of coated paper (coated face up) in a controlled atmosphere storage room. Two types of conditions were used: standard conditions $\left(\mathrm{T}=25{ }^{\circ} \mathrm{C}\right.$, humidity $=50 \%$ ) and tropical conditions $\left(\mathrm{T}=38{ }^{\circ} \mathrm{C}\right.$, humidity $=90 \%$ ). The MVTR (in $\mathrm{g} \mathrm{m}^{-2}$ day $^{-1}$ ) was determined by weighing the amount of water absorbed in 24 hours by the dessicant salt.

\section{Standard ethylene polymerization:}

Ethylene polymerizations were carried out in a $160 \mathrm{~mL}$ stainless steel autoclave purchased from Parr Instrument Co. Previous to the polymerization, the reactor had been set under an inert argon atmosphere and preheated to the desired temperature. In parallel, a $50 \mathrm{~mL}$ initiator aqueous solution with or without surfactant and $\mathrm{pH}$ regulator was degassed by argon bubbling for 15 minutes. This solution was loaded into the reactor through a cannula, under argon flow. Ethylene was introduced immediately after in the reactor, which marked the beginning of the polymerization. Ethylene pressure was maintained during the polymerization by small ethylene additions, making this type of polymerization a semi-batch process. After the desired polymerization duration, the reactor's jacket was cooled down by water. The reactor was then slowly degassed until reaching atmospheric pressure to collect the latex. A fraction of the 
obtained latex was dried for solids content measurement, which after subtraction of nonpolymeric species gave the polymer content (PC, \%). When the latex was stable, the PC was used to calculate the yield of the polymerization. The dried polymer was then used for polymer characterization (DSC, NMR, SEC).

\section{Results and discussion}

\section{Development of a negatively charged initiating and stabilizing system}

As interesting as they are, positively charged latexes currently find fewer applications. Free radical emulsion polymerization of ethylene with negatively charged initiator and surfactant was thus investigated. A first series of experiments was carried out using 4,4'-azobis(4cyanopentanoic acid) (ACPA, $1 \mathrm{~g} \mathrm{~L}^{-1}$ ) as an anionic equivalent of AIBA. Since ACPA has two carboxylic acid functions, it needs a slightly basic solution to dissolve. Thus, the polymerizations took place in presence of $\mathrm{NaHCO}_{3}\left(1 \mathrm{~g} \mathrm{~L}^{-1}\right)$, with or without surfactant (Sodium Dodecyl Sulfate, SDS). Small amounts of PE polymer in a stable latex were obtained $(\mathrm{PC} \approx 0.5 \%)$. Once the latex had been dried, a waxy polymer of very low molar mass was obtained. To increase the yields, different experimental conditions (ethylene pressure and surfactant concentration, $\mathrm{pH}$ ) were investigated. However, despite producing stable latexes, the amounts of polymer obtained remained low ( $\mathrm{PC} \leq 0.5 \%$ ). The feasibility of free radical emulsion polymerization of ethylene was then studied using a more common initiator, ammonium persulfate (APS). 
Table 1. Experimental conditions for FRPE in aqueous medium for the development of a negatively charged initiating and stabilizing system.

\begin{tabular}{cccccccc}
\hline Run & $\mathrm{pH}_{\mathrm{i}}$ & $\mathrm{pH}_{\mathrm{f}}$ & $\begin{array}{c}\text { Yield (g) } \\
(\mathrm{PC})(\%)\end{array}$ & $\begin{array}{c}\mathrm{Z}_{\mathrm{av}}(\mathrm{nm}) \\
(\text { poly })\end{array}$ & $\mathrm{T}_{\mathrm{m}}\left({ }^{\circ} \mathrm{C}\right)$ & $\mathrm{X}_{\mathrm{c}}(\%)$ & $\begin{array}{c}M_{\mathrm{n}}\left(\mathrm{g} \mathrm{mol}^{-1}\right) \\
(Ð)\end{array}$ \\
\hline $1^{a}$ & 5.4 & 2.8 & $0.59(1.2)$ & $95(0.26)$ & 88 & 17 & $700(6.3)$ \\
$2^{a, b}$ & 8.2 & 8.9 & $2.40(4.8)$ & $23(0.30)$ & 84 & 13 & $49400(2.9)$ \\
$3^{a, c}$ & 9.9 & 9.4 & $2.04(4.1)$ & $22(0.32)$ & 85 & 22 & $55000(2.7)$ \\
$4^{a, d}$ & 12.4 & 12.2 & $3.58(7.2)$ & $27(0.18)$ & 86 & 18 & $85000(7.0)$ \\
\hline
\end{tabular}

${ }^{a} \mathrm{t}=4 \mathrm{~h}, \mathrm{~T}=80^{\circ} \mathrm{C},[\mathrm{APS}]=0.84 \mathrm{~g} \mathrm{~L}^{-1},[\mathrm{SDS}]=3 \mathrm{~g} \mathrm{~L}^{-1}, 50 \mathrm{~mL} \mathrm{H}_{2} \mathrm{O}, \mathrm{P}_{\text {ethylene }}=100 \mathrm{bar}$, stirring rate $=250 \mathrm{rpm}$. ${ }^{b} \mathrm{pH}$ regulator: $\left[\mathrm{NaHCO}_{3}\right]=1 \mathrm{~g} \mathrm{~L}^{-1} \cdot{ }^{c} \mathrm{pH}$ regulator: $\mathrm{K}_{2} \mathrm{CO}_{3}\left(1.6 \mathrm{~g} \mathrm{~L}^{-1}\right)$. ${ }^{d} \mathrm{pH}$ regulator: $\mathrm{NaOH}\left(1 \mathrm{~g} \mathrm{~L}^{-1}\right)$.

Polymerizations of ethylene in presence of APS $\left(0.84 \mathrm{~g} \mathrm{~L}^{-1}\right)$ with surfactant (SDS, $\left.3 \mathrm{~g} \mathrm{~L}^{-1}\right)$ yielded a stable latex with $95 \mathrm{~nm}$ PE particles containing a negligible polymer amount $(0.59 \mathrm{~g}$, run 1 in Table 1). A pH drop from $5.4\left(\mathrm{pH}_{\mathrm{i}}\right.$ in Table 1) to $2.8\left(\mathrm{pH}_{\mathrm{f}}\right.$ in Table 1) before and after polymerization could be measured. When regulating the $\mathrm{pH}$ with salts such as $\mathrm{NaHCO}_{3}, \mathrm{~K}_{2} \mathrm{CO}_{3}$ or $\mathrm{NaOH}$ (runs 2 to 4 in Table 1) stable latexes exhibiting substantial amounts of polymer (PC $\geq$ $4 \%$ ) were obtained. No significant $\mathrm{pH}$ variation was observed before and after polymerization in these three cases.

These results concur with the well-known sensitivity of persulfate initiators to $\mathrm{pH}^{24-26}$ The need for a $\mathrm{pH}$ regulator for the emulsion polymerization of monomers such as ethylene-vinyl acetate mixtures ${ }^{27}$ or butadiene ${ }^{28}$ using persulfate initiators has been indeed reported in the literature. By comparison, the $\mathrm{pH}$ regulator is not necessary for emulsion polymerization of styrene. ${ }^{24}$ The emulsion polymerization of monomers such as butadiene or ethylene with persulfate initiators would thus require a steady, basic $\mathrm{pH}$ value to obtain significant amounts of polymer. 
This trend has been verified in our case for the emulsion polymerization of ethylene. Using different $\mathrm{pH}$ regulators, initial $\mathrm{pH}$ values between 8.2 and 12.4 were investigated (runs 2 to 4 in Table 1). Polymerization yields increased with increasing $\mathrm{pH}$. Higher decomposition rate of APS in alkaline conditions ${ }^{25,29}$ could partially explain these findings. However it is known that the polymerization rate is not strongly influenced by the initiator decomposition rate in conventional emulsion polymerization. It thus seems clear that the nature of the monomer plays a determinant role in our case as styrene does not lead to similar trends.

Particle sizes remained around $25 \mathrm{~nm}$ and high poly values were obtained by DLS (poly $>0.1$ ), indicating non-spherical, disc-like particle morphologies. ${ }^{9}$ Indeed, it has been evidenced in previous works that in the case of PE latexes a high poly value $(\geq 0.10)$ did not imply a poor stabilization or an heterogeneous particle size distribution but non-spherical particle shapes. Thermal properties of polethylenes remained the same, independently from the $\mathrm{pH}$ value $\left(\mathrm{T}_{\mathrm{m}} \approx\right.$ $90{ }^{\circ} \mathrm{C}, \mathrm{X}_{\mathrm{c}} \approx 20 \%$ ), indicating that the polymer microstructure was not affected by this parameter. For the next experiments, $\mathrm{NaHCO}_{3}\left(1 \mathrm{~g} \mathrm{~L}^{-1}\right)$ was chosen as the $\mathrm{pH}$ regulator.

\section{Influence of the surfactant concentration}

Having established the determinant role of $\mathrm{pH}$ on the synthesis of PE particles using APS as initiator, we next investigated the effect of SDS concentration for a fixed polymerization $\mathrm{pH}$ of 8.2. Polymerizations of ethylene were performed in aqueous solutions with SDS concentrations ranging from 0 to $5 \mathrm{~g} \mathrm{~L}^{-1}$ in presence of $\mathrm{NaHCO}_{3}$. Experimental conditions and results are reported in Table 2 (runs 2 and 5 to 9 in Table 2) and Figure 1. Without surfactant (run 5, Table 2), a stable latex was obtained, but with a low polymer content. The addition of SDS provided much more significant yields with an optimum reached for $5 \mathrm{~g} \mathrm{~L}^{-1}$ of SDS (run 9, Table 2 and 
Figure 1). Particle sizes decreased with surfactant concentration, until $5 \mathrm{~g} \mathrm{~L}^{-1}$. Above this concentration, the latexes were not stable anymore.

Table 2. Experimental conditions for FRPE in aqueous media for the investigation of the effect of surfactant concentration and kinetic study ${ }^{a}$

\begin{tabular}{|c|c|c|c|c|c|c|c|}
\hline Run & Duration (h) & $\begin{array}{l}{[\mathrm{SDS}]} \\
\left(\mathrm{g} \mathrm{L}^{-1}\right)\end{array}$ & $\begin{array}{l}\text { Yield (g) } \\
(\mathrm{PC})(\%)\end{array}$ & $\begin{array}{c}\mathrm{Z}_{\mathrm{av}}(\mathrm{nm}) \\
\quad(\text { poly })\end{array}$ & $\mathrm{T}_{\mathrm{m}}\left({ }^{\circ} \mathrm{C}\right)$ & $\mathrm{X}_{\mathrm{c}}(\%)$ & $\begin{array}{c}M_{\mathrm{n}}\left(\mathrm{g} \mathrm{mol}^{-1}\right) \\
(\bigoplus)\end{array}$ \\
\hline 5 & 4 & 0 & $0.77(1.5)$ & $91(0.03)$ & 89 & 24 & $3400(5.3)$ \\
\hline 6 & 4 & 1 & $1.27(2.5)$ & $58(0.01)$ & 88 & 22 & $57300(2.0)$ \\
\hline 7 & 4 & 2 & $1.79(3.6)$ & $37(0.10)$ & 87 & 26 & $230000(2.1)$ \\
\hline$(2)$ & 4 & 3 & $2.40(4.8)$ & $23(0.30)$ & 84 & 13 & $49400(2.9)$ \\
\hline 8 & 4 & 4 & $2.76(5.5)$ & $20(0.42)$ & 83 & 22 & $30000(4.2)$ \\
\hline 9 & 4 & 5 & $2.89(5.8)$ & $18(0.15)$ & 83 & 23 & $16600(4.7)$ \\
\hline 10 & 0.5 & 0 & $0.00(0.0)$ & - & - & - & - \\
\hline 11 & 1 & 0 & $0.00(0.0)$ & - & - & - & - \\
\hline 12 & 2 & 0 & $0.05(0.1)$ & $40(0.01)$ & nd & nd & - \\
\hline 13 & 3 & 0 & $0.40(0.8)$ & $79(0.02)$ & 88 & 18 & - \\
\hline$(5)$ & 4 & 0 & $0.74(1.5)$ & $91(0.03)$ & 89 & 24 & $3400(5.3)$ \\
\hline 14 & 6 & 0 & $0.96(1.9)$ & $108(0.01)$ & 90 & 19 & $7600(3.4)$ \\
\hline 15 & 0.5 & 3 & $0.20(0.4)$ & $11(0.43)$ & 85 & 11 & - \\
\hline 16 & 1 & 3 & $0.34(0.7)$ & $19(0.45)$ & 81 & 11 & $5200(5.2)$ \\
\hline 17 & 2 & 3 & $1.27(2.5)$ & $20(0.37)$ & 82 & 19 & $20000(4.7)$ \\
\hline 18 & 3 & 3 & $1.62(3.2)$ & $19(0.32)$ & 83 & 21 & $21500(3.7)$ \\
\hline (2) & 4 & 3 & $2.40(4.8)$ & $23(0.30)$ & 84 & 13 & $49400(2.9)$ \\
\hline 19 & 6 & 3 & $2.53(5.1)$ & $22(0.31)$ & 84 & 17 & $73300(2.2)$ \\
\hline
\end{tabular}




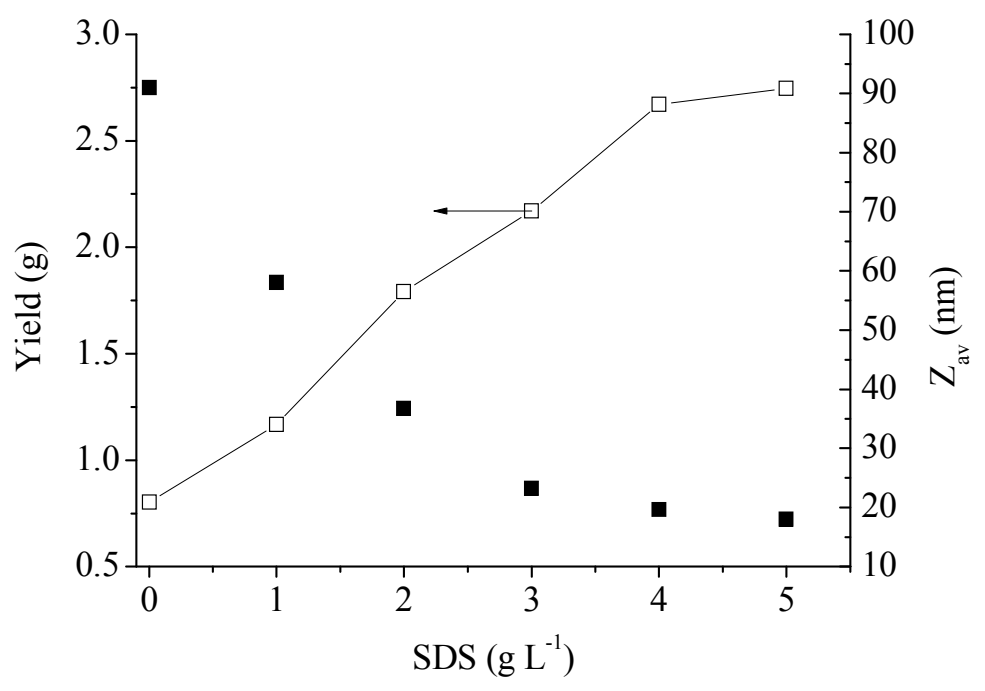

Figure 1. Influence of SDS concentration on polymer yields ( $\square)$ and particle sizes $\left(\mathrm{Z}_{\mathrm{av}}, \boldsymbol{\square}\right)$ during the synthesis of PE particles via FRPE in aqueous dispersed media using APS as initiator and $\mathrm{NaHCO}_{3}$ as $\mathrm{pH}$ regulator (runs 2 and 5 to 9, Table 2).

Above $2 \mathrm{~g} \mathrm{~L}^{-1}$ of SDS, the poly value measured by DLS was high $(\geq 0.10)$, indicating that the PE particles probably exhibited non-spherical morphologies. ${ }^{9}$ The non-spherical particle shape was indeed confirmed by cryo-TEM for run 2 (Figure 2). Even if it is difficult to obtain accurate particle dimensions from cryo-TEM, the particle size shows a good accordance with DLS, and confirms that the high poly value is likely due to the non-spherical shape of the particles rather to a high particle size heterogeneity. 


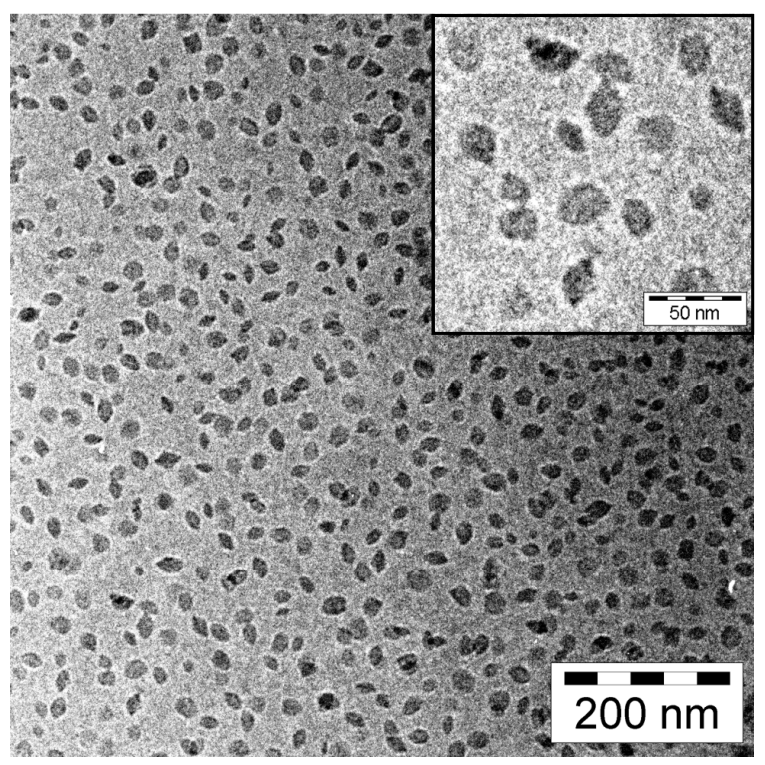

Figure 2. Cryo-TEM picture of a PE latex synthesized with $3 \mathrm{~g} \mathrm{~L}^{-1} \mathrm{SDS}$ (run 2, Table 1).

Despite the fact that average diameters measured by DLS assume a spherical shape for particles (and thus correspond to the equivalent spherical diameters of disk-like particles), the particle number $\mathrm{N}_{\mathrm{p}}$ was estimated according to equation (1). Figure 3 shows the dependence of $\mathrm{N}_{\mathrm{p}}$ on SDS concentration. It points out that the higher the surfactant concentration, the greater the number of particles. This figure illustrates the very strong particle nucleation taking place during emulsion polymerization of ethylene. 


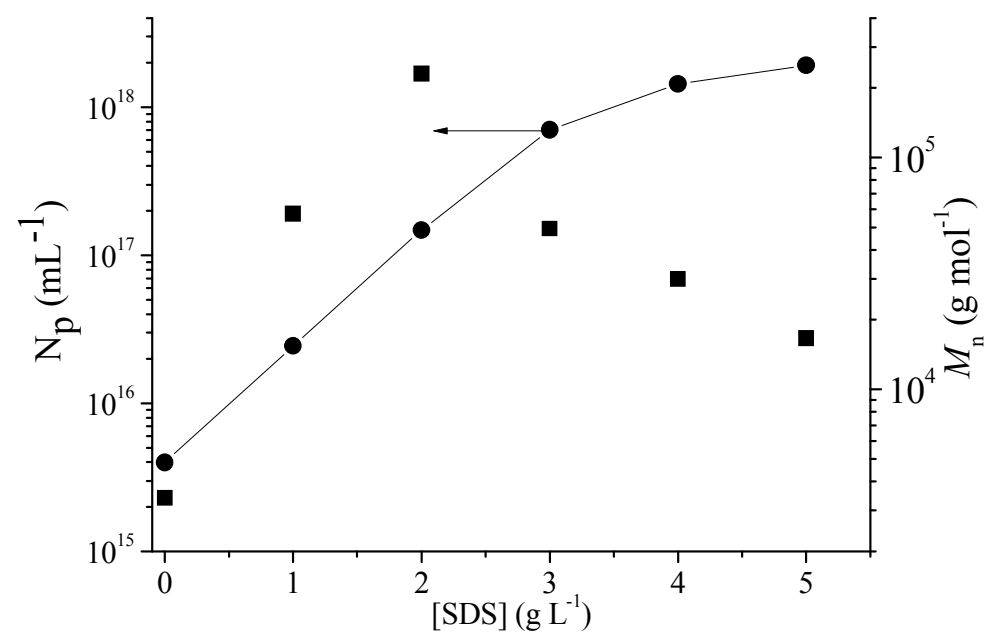

Figure 3. Influence of SDS concentration on the polymer molar mass $\left(M_{\mathrm{n}}, \boldsymbol{-}\right)$ and on the number of particles $\left(\mathrm{N}_{\mathrm{p}}, \bullet\right)$ during the synthesis of PE particles by FRPE in aqueous dispersed media (runs 2 and 5 to 9 , Table 2).

Figure 3 also indicates that the molar mass first increased with increasing surfactant concentration from 0 to $2 \mathrm{~g} \mathrm{~L}^{-1}$ (runs 5 to 7 , Table 2) and then significantly decreased. This is once again in contradiction with standard emulsion polymerization theory which usually predicts that the molar mass increases when the number of latex particles increases. The likeliest scenario is that a transfer reaction to the surfactant occurs, as already observed in early works of Mantell on free radical polymerization of ethylene in water. ${ }^{16}$ Indeed, the similarity between the alkane moiety of SDS and a polyethylene chain makes transfer reactions of growing PE macroradical to SDS possible, as it could be transferred to another polyethylene chain by in an intermolecular reaction, usually responsible of branches formations. There would thus be a competition between compartmentalization of radicals, responsible for higher molar masses, and transfer to the 
surfactant, which would shorten the chains. This competition favors at first the compartmentalization and higher molar masses, but as the surfactant concentration increases, molar masses end up decreasing. NMR studies failed to evidence this transfer to surfactant as it is not possible to find a common NMR solvent for both PE and sulfonate moieties.

\section{Kinetic studies of APS initiated FRPE, without or with SDS $\left(3 \mathrm{~g} \mathrm{~L}^{-1}\right)$}

To better understand the particle nucleation in absence or presence of SDS, kinetic studies were undertaken for both systems. From a practical viewpoint, this implied to carry out a new experiment for each investigated time as no withdrawal of sample was technically possible during the reaction. FRPE was thus carried out under 100 bar of ethylene, without SDS (runs 5 and 10 to 14, Table 2) and with $3 \mathrm{~g} \mathrm{~L}^{-1}$ of SDS (runs 2 and 15 to 19, Table 2). The polymerization durations spread from 0.5 to $6 \mathrm{~h}$. As observed in our earlier work on the synthesis of cationic PE latexes, yields increased with time in both cases (Figure 4). ${ }^{9}$ Whatever the polymerization time, higher yields were reached when SDS was present. Particle sizes increase was very strong without surfactant (Figure 5). The number of particles is almost constant (Figure 5), implying that particles are created at the beginning of the polymerization and grow bigger during the polymerization. In contrast, in presence of surfactant, particle sizes are constant with a rather narrow particle size distribution (vide supra) when yields increase (Figure 5, Table 2). Here, particles are created all along the polymerization. This seems to indicate that particles, continuously nucleated during polymerization, failed to grow bigger. These trends are very similar to those previously observed during the synthesis of cationic PE latexes with or without surfactant. ${ }^{9}$ Analogous results have been also evidenced in latexes of semi-crystalline polymers 
obtained by catalytic emulsion polymerization ${ }^{30}$, while it is not the case with amorphous polymers.

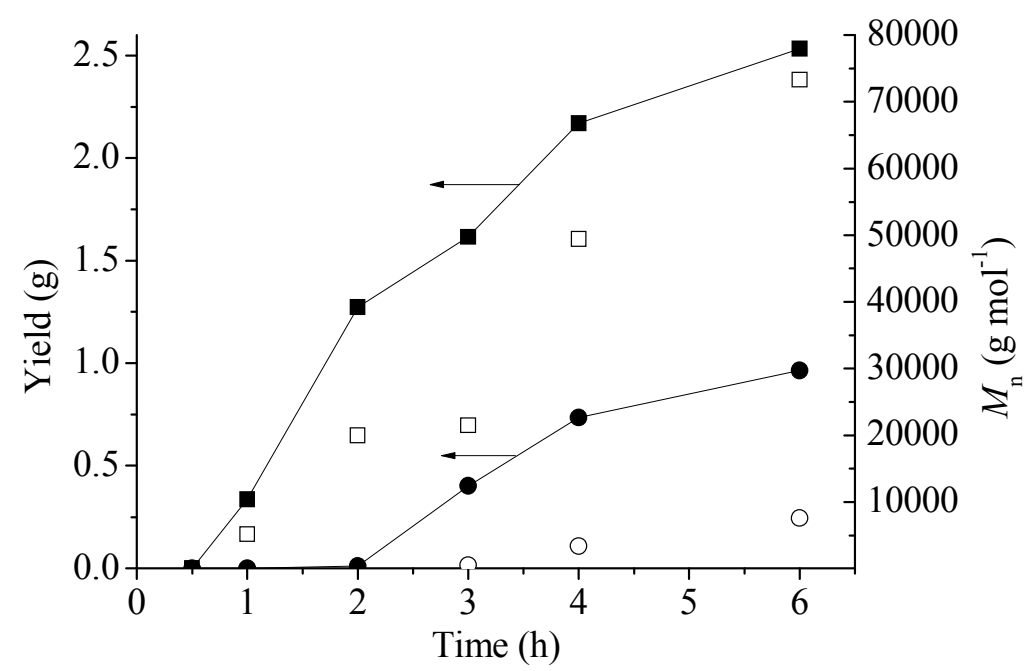

Figure 4. Polymer yields (• without surfactant and $\boldsymbol{\bullet}$ with surfactant, $3 \mathrm{~g} \mathrm{~L}^{-1}$ ) and molar masses ( $M_{\mathrm{n}}$, $\bigcirc$ without surfactant and $\square$ with surfactant) vs time curves during the synthesis of PE particles by FRPE in aqueous dispersed media using APS as initiator and SDS as surfactant (runs 2, 5 and 10 to 19 , Table 2).

Molar masses increased with time in both cases (Figure 4). However, the obtained molar masses were much higher in the case of FRPE in presence of surfactant (up to $M_{n} \approx 7.510^{4} \mathrm{~g} \mathrm{~mol}^{-}$ ${ }^{1}$ ), as already mentioned. Surprisingly, especially in the presence of surfactant, the molar masses increased with time, and thus with the polymer yield. We currently have no rational explanation for this phenomenon which deserves deeper investigation. 


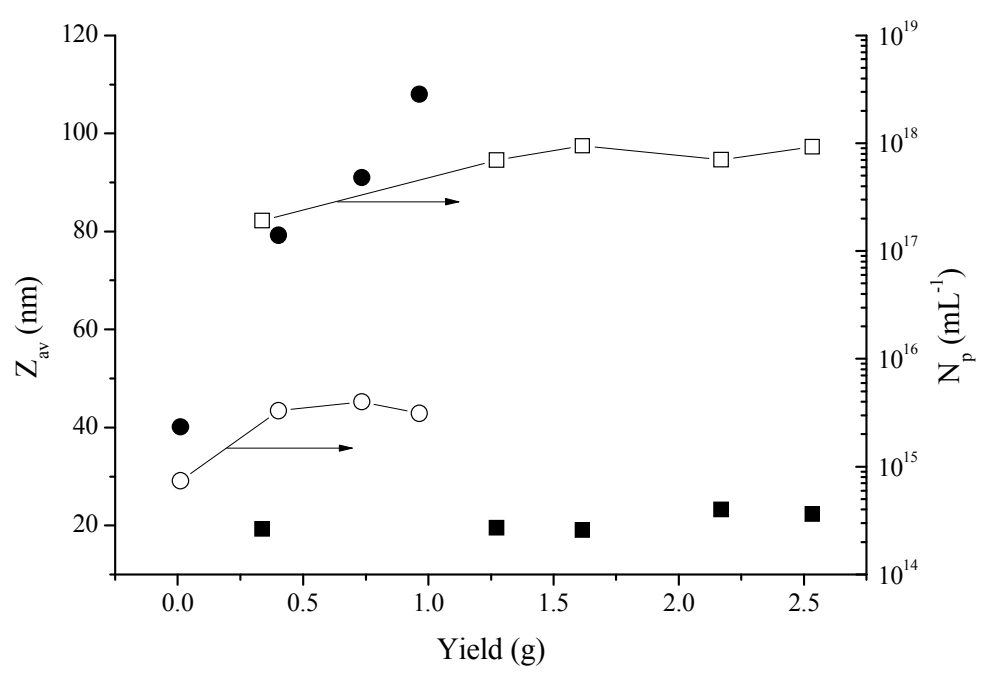

Figure 5. Particle sizes $\left(\mathrm{Z}_{\mathrm{av}}\right.$, $\bullet$ without surfactant and $\mathbf{m i t h}$ surfactant $)$ and particle numbers ( $\mathrm{N}_{\mathrm{p}}$, $\circ$ without surfactant and $\square$ with surfactant) vs yield curves during the synthesis of PE particles by FRPE in aqueous dispersed media using APS as initiator and SDS as surfactant (runs 2, 5 and 10 to 19 , Table 2).

\section{Towards higher solids contents}

Influence of ethylene pressure

In the next series of experiments, the effect of ethylene pressure has been investigated for a constant stirring rate of $250 \mathrm{rpm}$. Without (runs 5 and 20 to 22, Table 3) or with surfactant (runs 2 and 23 to 25, Table 3), yields, particle sizes and molar masses reached higher values when ethylene pressure was increased (Figure 6). In all cases, a stable latex was obtained. It can be noticed that in the absence of surfactant, particle sizes were multiplied by a factor of 3 (63 to 173 $\mathrm{nm}$ ) with increasing pressure from 50 to $200 \mathrm{bar}$, while yield increase was moderate ( 0.08 to 2.41 g). In contrast, in presence of $3 \mathrm{~g} \mathrm{~L}^{-1} \mathrm{SDS}$, yields increase was drastic (0.21 to $\left.6.46 \mathrm{~g}\right)$ while particle sizes were 3 times larger as well (16 to $42 \mathrm{~nm}$ ). Similar results were observed in our 
previous work on the synthesis of cationic PE latexes. ${ }^{9}$ As expected, very high molar masses have been reached with surfactant $\left(M_{\mathrm{n}}=2.510^{6} \mathrm{~g} \mathrm{~mol}^{-1}\right.$ under $\left.200 \mathrm{bar}\right)$, but these were much lower without surfactant: $M_{\mathrm{n}}=8.510^{5} \mathrm{~g} \mathrm{~mol}^{-1}$ under 200 bar.

Table 3. Experimental conditions for FRPE in aqueous media for the investigation of the effect of ethylene pressure, stirring rate and feasibility of high solids content ${ }^{a}$

\begin{tabular}{cccccccc}
\hline Run & $\begin{array}{c}\text { Stirring } \\
\text { rate (rpm) }\end{array}$ & $\mathrm{P}_{\text {ethylene }}($ bar $)$ & $\begin{array}{c}\text { Yield (g) } \\
(\mathrm{PC})(\%)\end{array}$ & $\begin{array}{c}\mathrm{Z}_{\mathrm{av}}(\mathrm{nm}) \\
(\text { poly })\end{array}$ & $\begin{array}{c}\mathrm{T}_{\mathrm{m}} \\
\left({ }^{\circ} \mathrm{C}\right)\end{array}$ & $\begin{array}{c}\mathrm{X}_{\mathrm{c}} \\
(\%)\end{array}$ & $\begin{array}{c}M_{\mathrm{n}}\left(\mathrm{g} \mathrm{mol}^{-1}\right) \\
(\nexists)\end{array}$ \\
\hline $20^{b}$ & 250 & 50 & $0.08(0.2)$ & $63(0.08)$ & 80 & 2 & - \\
$(5)^{b}$ & 250 & 100 & $0.74(1.5)$ & $91(0.03)$ & 89 & 24 & $3400(5.3)$ \\
$21^{b}$ & 250 & 150 & $1.16(1.3)$ & $120(0.02)$ & 95 & 24 & $14700(3.4)$ \\
$22^{b}$ & 250 & 200 & $2.41(4.8)$ & $173(0.04)$ & 91 & 32 & $84700(4.1)$ \\
\hline 23 & 250 & 50 & $0.21(0.4)$ & $16(0.32)$ & 51 & 3 & $4900(1.4)$ \\
$(2)$ & 250 & 100 & $2.40(4.8)$ & $23(0.30)$ & 84 & 13 & $49400(2.9)$ \\
24 & 250 & 150 & $4.61(9.2)$ & $30(0.25)$ & 91 & 23 & $220000(2.4)$ \\
25 & 250 & 200 & $6.46(12.9)$ & $42(0.20)$ & 91 & 26 & $585000(2.3)$ \\
\hline$(2)$ & 250 & 100 & $2.40(4.8)$ & $23(0.30)$ & 84 & 13 & $49400(2.9)$ \\
26 & 500 & 100 & $4.90(9.8)$ & $23(0.24)$ & 89 & 22 & - \\
27 & 750 & 100 & $6.70(13.4)$ & $26(0.20)$ & 91 & 25 & - \\
28 & 950 & 100 & $5.93(11.9)$ & $24(0.20)$ & 91 & 25 & - \\
\hdashline$(27)$ & 750 & 100 & $6.70(13.4)$ & $26(0.20)$ & 91 & 25 & $260000(3.0)$ \\
29 & 750 & 150 & $15.17(30.3)$ & $63(0.11)$ & 84 & 18 & $2.110^{6}(2.4)$ \\
30 & 750 & 200 & $24.00(-)$ & Unstable & 96 & 33 & $-{ }^{\mathrm{d}}$ \\
31 & 750 & 250 & $32.50(-)$ & Unstable & 102 & 44 & $-{ }^{\mathrm{d}}$ \\
\hline
\end{tabular}

${ }^{a} \mathrm{t}=4 \mathrm{~h}, \mathrm{~T}=80^{\circ} \mathrm{C},[\mathrm{APS}]=0.84 \mathrm{~g} \mathrm{~L}^{-1}, \mathrm{pH}$ regulator: $\left[\mathrm{NaHCO}_{3}\right]=1 \mathrm{~g} \mathrm{~L}^{-1},[\mathrm{SDS}]=3 \mathrm{~g} \mathrm{~L}^{-1}, 50 \mathrm{~mL} \mathrm{H}_{2} \mathrm{O} .{ }^{b}$ Same experimental conditions as ${ }^{a}$ without SDS. ${ }^{c} \mathrm{t}=4 \mathrm{~h}, \mathrm{~T}=70^{\circ} \mathrm{C},[\mathrm{AIBA}]=1 \mathrm{~g} \mathrm{~L}^{-1},[\mathrm{CTAB}]=1 \mathrm{~g} \mathrm{~L}^{-1}, 50 \mathrm{~mL} \mathrm{H}_{2} \mathrm{O}$, ${ }^{\mathrm{d}}$ Exclusion limit of SEC columns. 


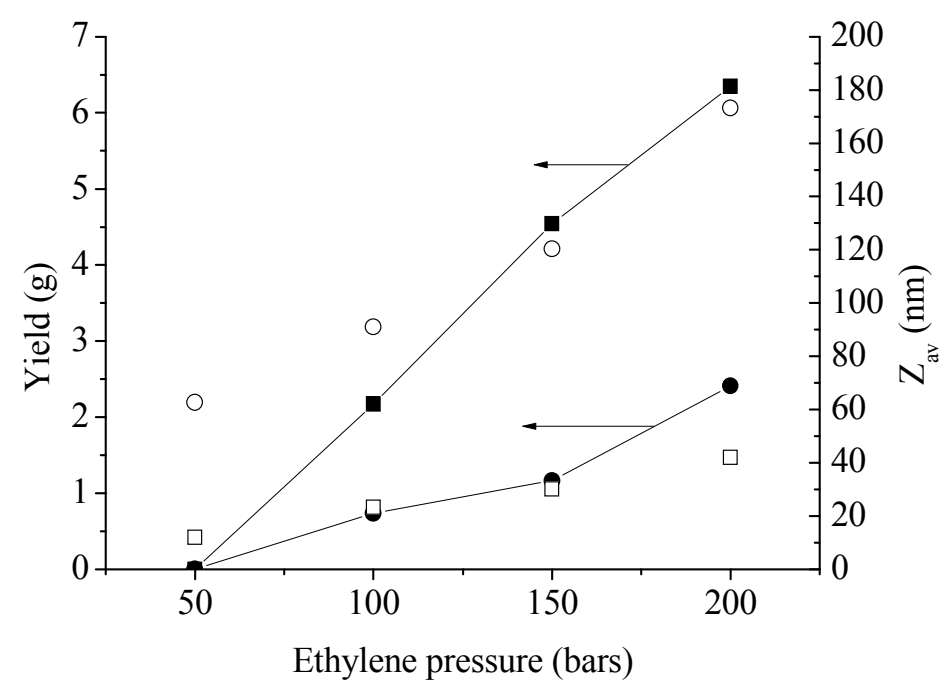

Figure 6. Effect of ethylene pressure on polymer yields (• without surfactant and $\boldsymbol{\bullet}$ without surfactant) and on particle sizes ( $\mathrm{Z}_{\mathrm{av}}$, $\bigcirc$ without surfactant and $\square$ with surfactant) during the synthesis of PE particles via FRPE in aqueous dispersed media (runs 2, 5 and 20 to 25, Table 3).

${ }^{13} \mathrm{C}$ NMR analysis was used to determine the branching degree of samples obtained for ethylene pressures of 50, 100, 150 and 200 bar, respectively (runs 23, 2, 24 and 25 in Table 3). ${ }^{23}$ The branching density decreases with increasing ethylene pressure, in agreement with DSC measurements (the crystallinity increases, Table 3). Indeed, the formation of polymer crystals is hindered by branches. This decrease in branching degree is probably due to higher monomer concentration when its pressure increases, thus favoring a linear growth of the chains (i.e. propagation) rather than intermolecular transfer reactions. When compared to a LDPE produced by an industrial process provided by Alfa-Aesar, the PE produced using emulsion polymerization under mild conditions exhibits a much lower crystallinity and a much higher branching density. 
Indeed, the industrial sample crystallinity is around $40 \%$, which is much higher than the 10 to 20 $\%$ of the PEs obtained by FRPE in water. The branching density range of the latter is of 24 to 50 branches / $1000 \mathrm{C}$ when the industrial sample possesses only 13 branches / $1000 \mathrm{C}$. Actually, with a more branched structure than an industrial LDPE, the PE produced by free radical emulsion polymerization relates more to very low density polyethylene (VLDPE). ${ }^{22}$ This is confirmed by the melting temperatures and crystallinities measured on our samples.

\section{Effect of the stirring rate}

In a heterogeneous polymerization process, the stirring rate is a decisive parameter which will influence the colloidal properties of the obtained latex. ${ }^{31}$ Accordingly, the effects of stirring rate on FRPE in aqueous media using an anionic initiating and stabilizing system were investigated at an ethylene pressure of 100 bar (runs 2 and 26 to 28, Table 3). Yields were multiplied by a factor 3 when increasing the stirring rate from 250 to $950 \mathrm{rpm}$, without latex destabilization. Particle sizes remained unchanged, around $25 \mathrm{~nm}$, with high poly values indicating non-spherical morphologies, whatever the stirring rate. The increase in yields can be explained by a better renewing of the ethylene-water interface.

The fact that particle sizes were not affected by stirring rate could originate from the crystallinity of PE inside latex particles. One can imagine that crystallinity protects the particles from coalescence phenomena, in a way similar to what can be observed for the synthesis of polystyrene particles in presence of a relatively high amount of cross-linker, which would favor the nucleation of new particles. ${ }^{32}$ Consequently, as yields increased and particle sizes remained constant, the number of particles increased with stirring rate, as shown in Figure 7. This effect was very important between 250 and $500 \mathrm{rpm}$ and then became less pronounced. By comparison 
in a conventional emulsion polymerization process where the polymer would be totally amorphous, a higher shear rate would increase coalescence phenomena and reduce the number of particles, as it is the case for butadiene emulsion polymerization. ${ }^{33}$ Nevertheless, the influence of crystallinity on particle formation should be considered with care because crystallinity values of bulk PE are very low $(<30 \%)$, and latex particles are mostly composed of amorphous PE. Investigations on thermal properties of PE latex itself will confirm that these hypotheses are subject to caution, as shown below.

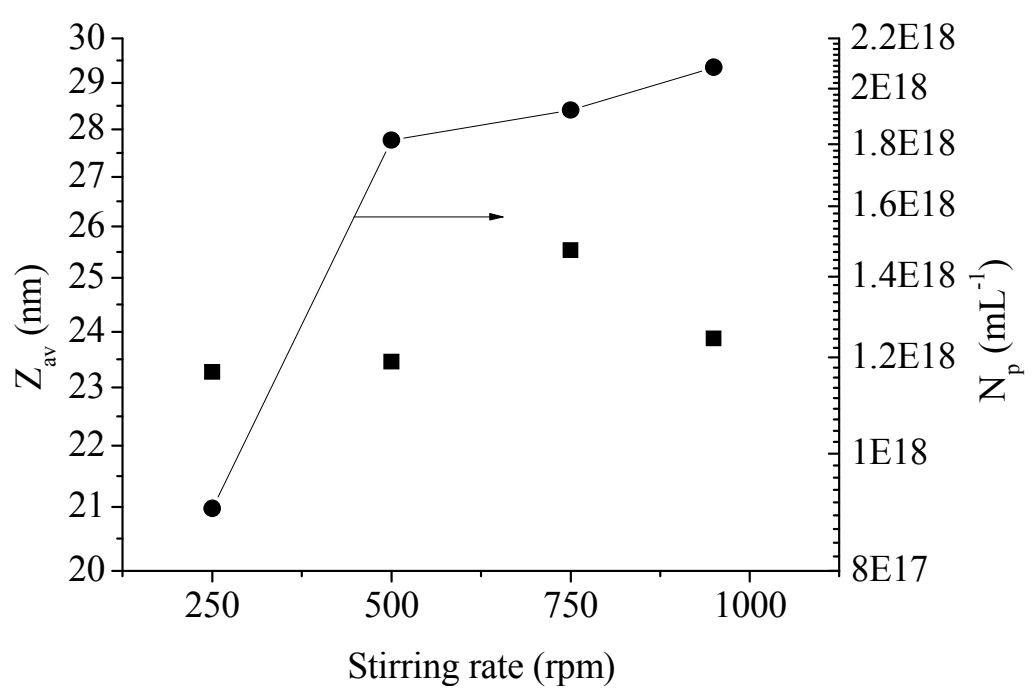

Figure 7. Evolution of the particle sizes $\left(\mathrm{Z}_{\mathrm{av}}, \boldsymbol{\square}\right)$ and the number of particles $\left(\mathrm{N}_{\mathrm{p}}, \bullet\right)$ with the stirring rate during the synthesis of PE particles via FRPE in aqueous dispersed media (runs 2 and 26 to 28 , Table 3 ). 
In order to further assess the influence of stirring in our process, we next investigated the effect of stirring rate on the melting temperature and crystallinity of PE isolated from the latex. Figure 8 shows an increase of both series of data. According to the aforementioned study on the effects of pressure in FRPE in aqueous media, this change in thermal properties is the reflection of a change in the structure of the PE chains. Indeed, a higher crystallinity has been identified as the result of a less branched polymer. As explained with the effect of ethylene pressure on the structure of the chains, a better monomer provision by higher stirring may help create more linear chains (intermolecular reactions are disfavored) and thus a more crystalline polymer, although still less crystalline than an industrial LDPE.

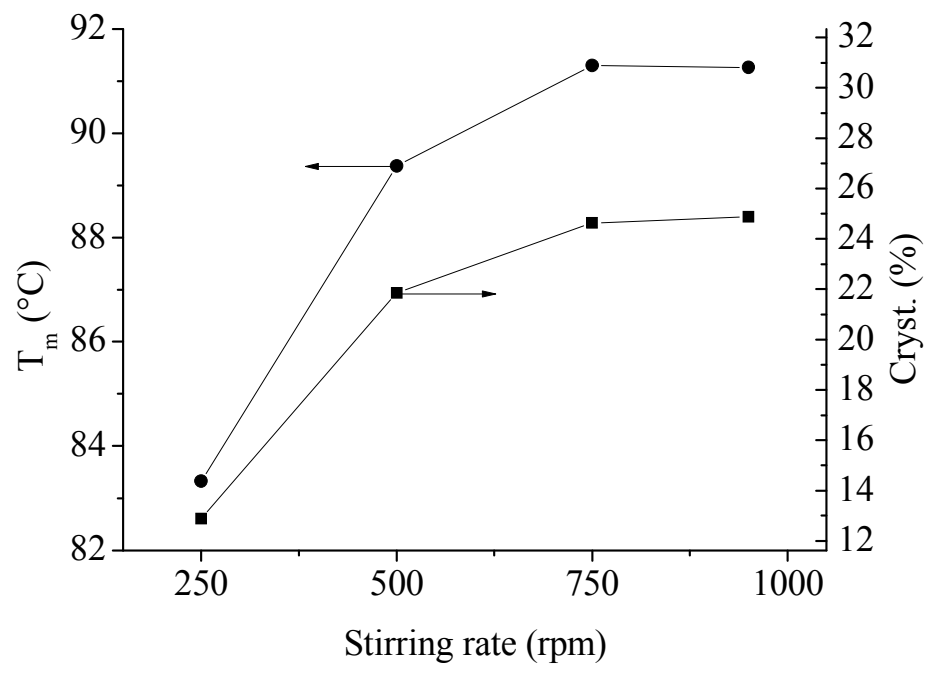

Figure 8. Effect of stirring rate on the melting temperature $\left(T_{m}, \bullet\right)$ and crystallinity $(\boldsymbol{a})$ of PE particles synthesized by FRPE in aqueous dispersed media (runs 2 and 26 to 28, Table 3). 


\section{Increase of the solids content}

To make this FRPE in aqueous media system interesting for further applications, we next investigated the possibility to increase the solids content. To do so, the range of ethylene pressures has been narrowed to $100-250$ bar and the stirring rate increased to $750 \mathrm{rpm}$ instead of the usual $250 \mathrm{rpm}$ to favor a fast renewing of the ethylene/water interface and thus a better monomer supply to the particles (runs 27 and 30 to 31, Table 3). Yields were indeed increased, causing the latexes to be destabilized by the high amounts of PE produced under 200 and 250 bar of ethylene, where 24 and $32 \mathrm{~g}$ of polymer were produced, respectively, in $50 \mathrm{~mL}$ of aqueous dispersion (runs 30 and 31 in Table 3). In these two cases, the yield was obtained by drying the whole content of the reactor. Nevertheless, under 150 bar of ethylene, a stable latex was obtained with a $30 \%$ solids content and an average particle diameter of $63 \mathrm{~nm}$ (run 29, Table 3). These high polymerization activities often go along with high molar masses as it was also the case here $\left(M_{\mathrm{n}}=2.110^{6} \mathrm{~g} \mathrm{~mol}^{-1}\right)$. Higher molar masses seem to be obtained for the higher ethylene pressures (200 and 250 bar), as the corresponding polyethylenes flowed directly through the columns without retention. Our SEC apparatus was consequently not able to give us valid molar mass values.

\section{Thermal properties of PE latexes}

While polyethylenes isolated from the latex can be analyzed by DSC giving access to the thermal properties of the bulk material, the measurement of the thermal properties directly on the 
latex is much more instructive. Indeed DSC analysis shows that the crystallization of PE occurs at a much lower temperature when polymer is located into the confined environment of a latex nanoparticle than under its bulk form. ${ }^{34,35}$ On the other hand, no significant differences between melting temperature of bulk PE and confined PE is observed. These phenomena have also been evidenced on PE dispersions made by catalytic processes ${ }^{10-14}$ and more generally on semicrystalline polymers under situations of confined environment (nanoparticles, ultrathin films, block copolymers mesophases...). ${ }^{36}$ This phenomenon, usually referred as supercooling, evidences a change of nucleation mechanism from heterogeneous nucleation in the bulk to surface or homogeneous nucleation in the confined situation. The intensity of this phenomenon can be quantified by $\Delta \mathrm{T}=\mathrm{T}_{\mathrm{c}}{ }^{\text {Bulk }}-\mathrm{T}_{\mathrm{c}}^{\text {Latex }}$ (with $\mathrm{T}_{\mathrm{c}}^{\text {Bulk }}$ the crystallization temperature in the bulk polymer and $\mathrm{T}_{\mathrm{c}}{ }^{\text {Latex }}$ the crystallization temperature of the particles in the latex).

This supercooling effect has been investigated for a range of latexes synthesized using different SDS concentrations (runs 2 and 5 to 9 in Table 2) and the expected trends were effectively observed (exemplified for run 7 in Figure 9). 


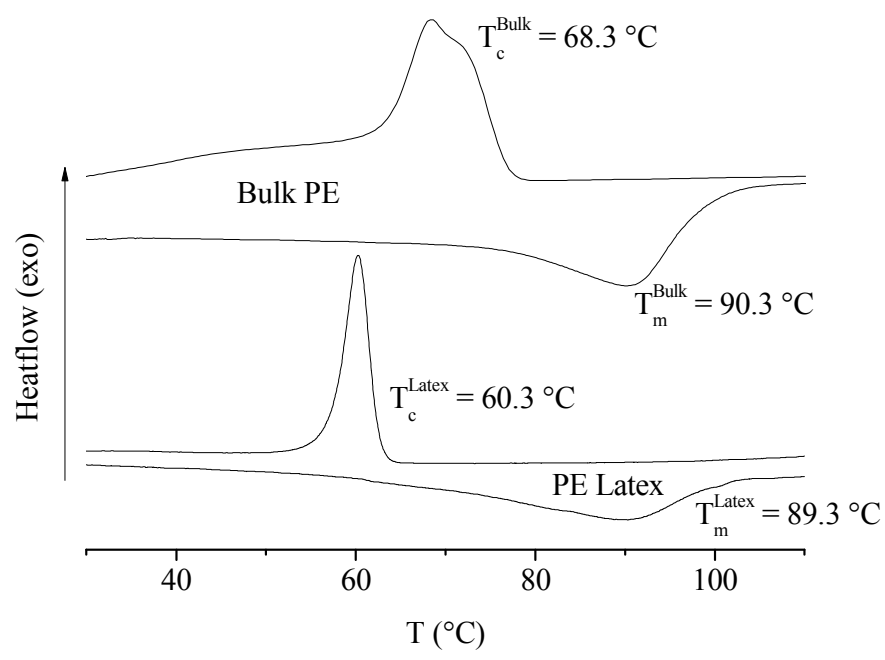

Figure 9. DSC analysis of a PE latex obtained by FRPE in aqueous dispersed media (run 5 in Table 2) compared to a bulk PE obtained by drying the same latex.

In matter of supercooling, the critical parameter to consider is the size of the confined domains, that is in our case the size of latex nanoparticles. Figure 10 shows that the depression of crystallization temperature of $\mathrm{PE}$ in latex, that is the intensity of supercooling, increases with decreasing nanoparticle size. Surfactant-induced supercooling can be ruled out by the fact that supercooling in a latex synthesized without surfactant but under a higher ethylene pressure, thus with bigger particles, gives a different supercooling value (data not shown).

The stability of the latex during DSC analysis is also very appealing. Indeed the latexes were submitted to temperatures up to $130{ }^{\circ} \mathrm{C}$ two times and were still stable afterwards as evidenced by DLS analyses of the resulting latex, which indicated no change of the particle size after thermal treatments. This indicates that PE can melt and crystallize inside nanoparticles of the latex without affecting the colloidal stability. Use of these PE latexes for phase change materials (PCM) applications such as heat transfer fluids (HTF) could be then envisaged. ${ }^{37}$ 


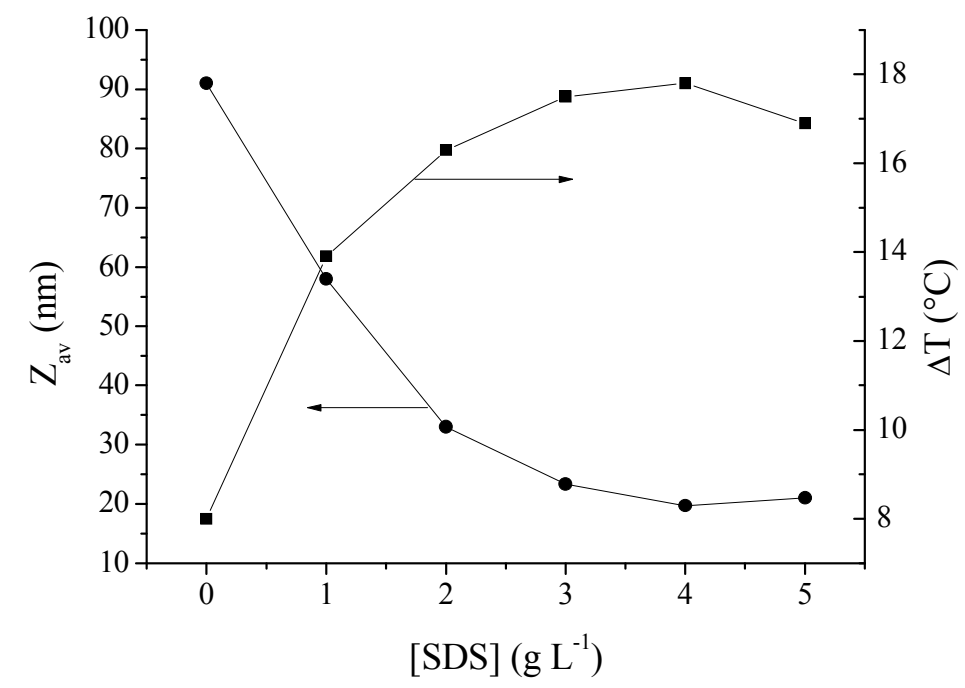

Figure 10. Particle sizes $\left(Z_{\mathrm{av}}, \bullet\right)$ and quantification of the supercooling effect $(\Delta \mathrm{T}, \mathbf{m})$ vs surfactant concentration (runs 2 and 5 to 9 , Table 2).

Another important conclusion can be drawn from the study of thermal properties of PE latex. Indeed, low $T_{\mathrm{c}}$ values for PE inside the latex particles indicate that during polymerization at $80{ }^{\circ} \mathrm{C}$, PE could be amorphous and would then crystallize during the cooling process of the latex at the end of the polymerization. This could strongly impact some of our interpretations on the influence of crystallinity on particle formation. Indeed, the process of PE crystallization under the polymerization conditions (i.e. under high pressures of ethylene) is difficult to assess. More investigations are necessary to precisely evaluate if, during the polymerization process, $\mathrm{PE}$ will crystallize as it is formed or will remain amorphous.

\section{Water-repellency properties of films obtained from PE latex}


Coatings applications are usually targeted for polymer latexes. In the case of polyethylene the apolar character of the polymer could lead to attractive barrier properties to water. Commercial aqueous wax dispersions, obtained by redispersion of bulk PE in water as described in the introduction, are indeed used for coating applications in particular for paper industry.

We evaluated our PE latexes for coatings application on paper substrate and compared them with commercial wax dispersions. To this purpose, PE latexes produced by free radical emulsion polymerization in our laboratory were coated on paper (vegetable parchment, $75 \mathrm{~g} \mathrm{~m}^{-2}$ ), to evaluate their effectiveness as protective coating against water. Aiming for a good interaction with the negatively charged cellulose, cationic latexes were used. They were synthesized using cationic initiator (AIBA, $1 \mathrm{~g} \mathrm{~L}^{-1}$ ) and surfactant (CTAB, $1 \mathrm{~g} \mathrm{~L}^{-1}$ ) under 250 bar of ethylene at 70 ${ }^{\circ} \mathrm{C}$ for 4 hours with a stirring rate of $250 \mathrm{rpm}$ according to our previous work. ${ }^{9}$ The solids content of the produced latex was increased to $30 \%$ by evaporating water for the coating needs, without destabilization or major average particle size alteration $\left(\mathrm{Z}_{\mathrm{av}} \approx 50 \mathrm{~nm}\right)$. The coating was performed at $120^{\circ} \mathrm{C}$ instead of the usual $160{ }^{\circ} \mathrm{C}$ used in industry. Two factors can account for this decrease of the coating temperature. Firstly, the lower melting temperatures of the PE contained in the latexes: the PE isolated from the latexes produced in our laboratory melts around $90{ }^{\circ} \mathrm{C}$ instead of 98-115 ${ }^{\circ} \mathrm{C}$ for a usual LDPE. ${ }^{17}$ Secondly, the PE nanoparticles obtained from emulsion polymerization are much smaller than the particles present in a wax dispersion, which are a few microns large. ${ }^{6}$ Indeed, smaller particles have been reported to decrease the minimum filmforming temperature (MFFT). ${ }^{38}$ The obtained film was homogeneously shiny with no visible cracks. Furthermore, water-repellent properties of the coated paper were investigated and compared to papers coated with a commercial wax dispersion. As observed in Figure 11, the commercial wax dispersion yields films with a good resistance to water vapors under tropical 
conditions (Figure 11a) and to liquid water (Figure 11c), but the PE latex from our laboratory gave better results against water vapors under standard conditions (Figure 11b). These results are quite promising, given that the commercial wax dispersion is formulated and specially made for this type of application.

Other substrates can be envisaged (fabrics, concrete, wood...) and depending on their surface charges, anionic or cationic PE latexes will be preferred, thus giving a very wide application range.
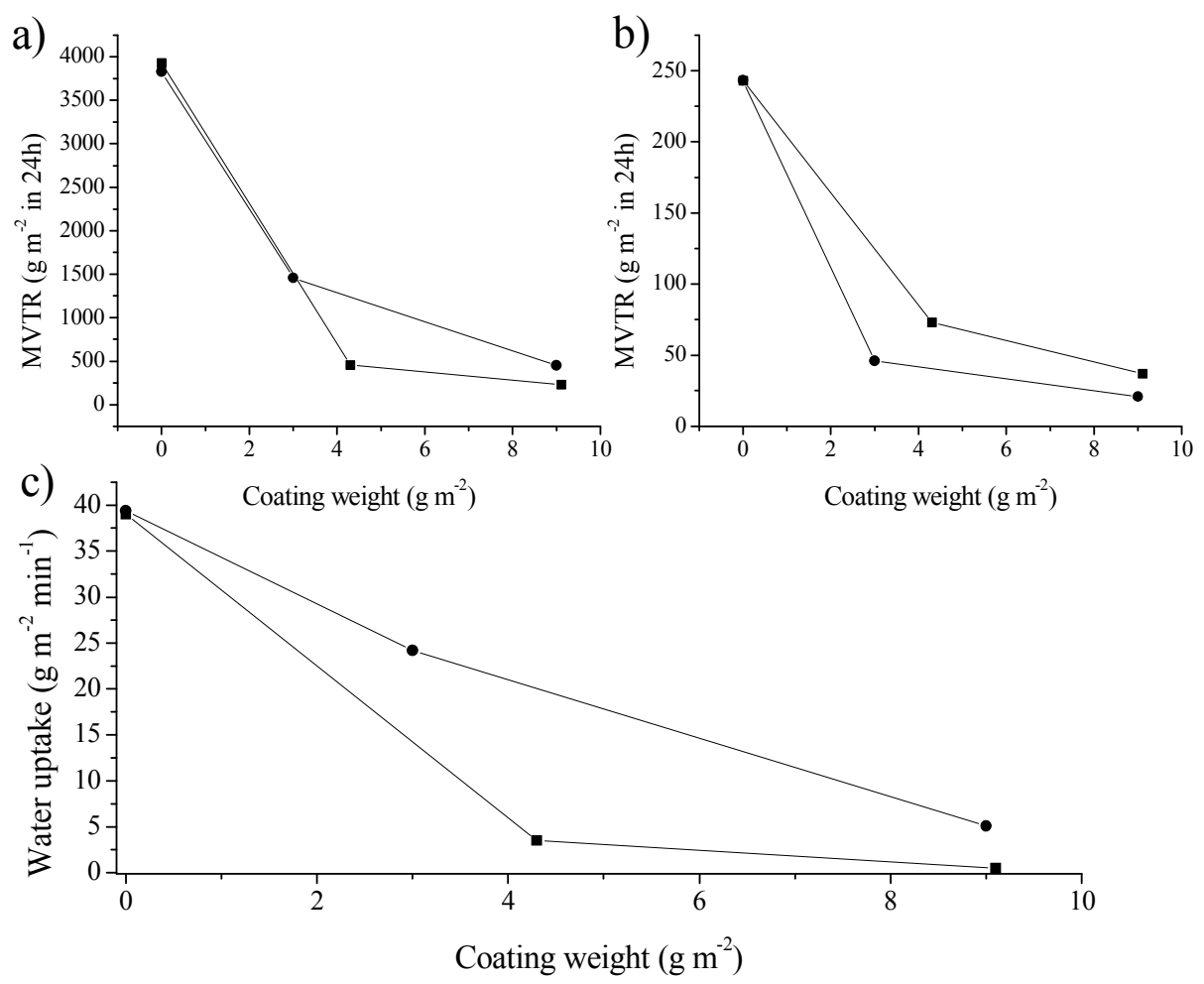

60

Figure 11. a) Moisture vapor transmission rate (MVTR) under tropical conditions $\left(\mathrm{T}=38{ }^{\circ} \mathrm{C}\right.$, Humidity $=90 \%), \mathrm{b})$ MVTR under standard conditions $\left(\mathrm{T}=25{ }^{\circ} \mathrm{C}\right.$, Humidity $\left.=50 \%\right)$ and $\left.\mathrm{c}\right)$ 
Water uptake during a Cobb test in standard conditions $\left(25^{\circ} \mathrm{C}\right)(\bullet$ PE latex from FRPE in aqueous media, commercial wax dispersion).

\section{Conclusions}

Free radical emulsion polymerization of ethylene has been successfully performed using an anionic stabilizing (SDS) and initiating system (APS). The use of a $\mathrm{pH}$ regulator was decisive to obtain significant yields. In absence of surfactant, stable PE latexes of low polymer contents, consisting of small sphere-like PE nanoparticles $\left(\mathrm{Z}_{\mathrm{av}} \approx 100 \mathrm{~m}\right)$, have been synthesized. With the addition of SDS, polymer contents are higher and the PE particles much smaller $\left(\mathrm{Z}_{\mathrm{av}} \approx 20 \mathrm{~nm}\right)$, presenting non-spherical morphologies. High molar masses were attained $\left(M_{\mathrm{n}}=2.310^{5} \mathrm{~g} \mathrm{~mol}^{-1}\right)$, despite possible transfer reactions to the surfactant. Different nucleation mechanisms have been proposed, depending on the presence of surfactant or not, but some interpretations, in particular the moment of crystallization of PE in the particles (during polymerization or during the cooling down of the latexes inside polymerization reactor) are still subject to debate.

To make FRPE in aqueous media viable for applications, the synthesis of high solids content latexes was investigated. To do so, ethylene pressure and stirring rate were varied. An increase in ethylene pressure led to higher solids contents, larger particles and higher molar masses, up to $M_{\mathrm{n}}$ $=2.510^{6} \mathrm{~g} \mathrm{~mol}^{-1}$. When investigating the effects of stirring rate in presence of surfactant, an 
important process parameter for emulsion polymerization, no influence on particle sizes was evidenced but the polymer content drastically increased resulting in an increase of the particle number. By combining higher pressures and stirring rates, stable latexes with polymer contents up to $30 \%$ could be successfully obtained. Both parameters appeared to improve the monomer feed to the growing chains, leading to slightly less branched and thus more crystalline PEs.

A supercooling phenomenon, whose governing parameter seems to be particle size, has been evidenced when studying the thermal properties of the latexes. Latexes stability was not affected after being submitted to extreme temperatures during DSC analysis $\left(0\right.$ to $\left.130^{\circ} \mathrm{C}\right)$. To estimate the water repellency properties of the PE films, our cationic latexes were coated on vegetable parchment. The low melting point of the PE and the small particle sizes allowed a coating temperature of $120{ }^{\circ} \mathrm{C}$ instead of the usual $160{ }^{\circ} \mathrm{C}$ used for commercial wax dispersions. Permeability to water was measured (Cobb test and MVTR) on the coated paper and showed promising results without even formulating the latex, especially against water vapor.

\section{Author Information \\ *E-mail: vincent.monteil@univ-lyon1.fr}

\section{Acknowledgments}

ANR (Agence Nationale de la Recherche) and competitiveness clusters AXELERA and PLASTIPOLIS are acknowledged for financial support (project FRaPE; ANR 2011 JS08 008 01). The authors thank Pierre-Yves Dugas for his help with cryo-TEM and DLS analyses, Olivier Boyron for SEC analyses and Jean-Pierre Broyer and Sébastien Norsic for technical support. We 
are grateful to the NMR Polymer Center of Institut de Chimie de Lyon (FR5223) for assistance and access to the NMR facilities. We also thank Dr. Christophe Boisson, Pr. Bernadette Charleux, Dr. Roger Spitz and Dr. Timothy McKenna for fruitful discussions.

\section{Supporting information available}

${ }^{13} \mathrm{C}$ NMR spectra of PE with branching assignments.

\section{References}

(1) Soares, J.; Simon, L. C. Coordination Polymerization In Handbook of Polymer Reaction Engineering; Meyer, T.; Keurentjes, J., Eds.; WILEY-VCH Verlag GmbH \& Co. KGaA: Weinheim, 2005; pp. 365-430.

(2) Kalyon, D. M.; Chiou, Y.-N.; Kovenklioglu, S.; Bouaffar, A. Polym Eng Sci 1994, 34, 804-814.

(3) Aggarwal, S. L.; Sweeting, O. J. Chem Rev 1957, 57, 665-742.

(4) Müllhaupt, R. Macromol Chem Phys 2003, 204, 289-327.

(5) Engels, T.; Foerster, T.; Klink, C.; Wahle, B.; Waltenberger, P. Process for the production of storage stable wax dispersions. U.S. Patent 0005723137A, March 3, 1998. 
(6) Gravatt, W. M.; Kocur, M. A.; Leotsakos, G.; Smith, C. P. Novel wax dispersion formulations, method of producing same, and uses. European Patent 2283094B1, October 10, 2011.

(7) Grau, E.; Broyer, J.-P.; Boisson, C.; Spitz, R.; Monteil, V. Polym. Chem. 2011, 2, 2328.

(8) Grau, E.; Broyer, J.-P.; Boisson, C.; Spitz, R.; Monteil, V. Macromolecules 2009, 42, $7279-7281$.

(9) Grau, E.; Dugas, P.-Y.; Broyer, J.-P.; Boisson, C.; Spitz, R.; Monteil, V. Angew Chem Int Ed 2010, 49, 6810-6812.

(10) Mecking, S.; Monteil, V.; Huber, J.; Kolb, L.; Wehrmann, P. Macromol. Symp. 2006, 236, $117-123$.

(11) Mecking, S. Colloid Polym. Sci. 2007, 285, 605-619.

(12) Bauers, F. M.; Thomann, R.; Mecking, S. J. Am. Chem. Soc. 2003, 8838-8840.

(13) Kolb, L.; Monteil, V.; Thomann, R.; Mecking, S. Angew Chem 2005, 433-436.

(14) Weber, C. H. M.; Chiche, A.; Krausch, G.; Rosenfeldt, S.; Ballauff, M.; Harnau, L.; Göttker-Schnetmann, I.; Tong, Q.; Mecking, S. Nano Lett. 2007, 7, 2024-2029.

(15) Yu, S.-M.; Mecking, S. Macromolecules 2009, 42, 3669-3673.

(16) Stryker, H. K.; Mantell, G. J.; Helin, A. F. J Polym. Sci Part C 1969, 27, 37-48.

(17) Helin, A. F.; Stryker, H. K.; Mantell, G. J. J. Appl. Polym. Sci. 1965, 9, 1797-1805.

(18) Stryker, H. K.; Helin, A. F.; Mantell, G. J. 1965. 
(19) Suwa, T.; Nakajima, H.; Takehisa, M.; Machi, S. Polym Lett Ed 1975.

(20) Hopff ; Kern Mod. Plast. 1946, 153-160 and 206-220.

(21) Grau, E.; Broyer, J.-P.; Boisson, C.; Spitz, R.; Monteil, V. Phys. Chem. Chem. Phys. 2010, 12, 11665-11669.

(22) Peacock, A. J. Handbook of Polyethylene: Structures: Properties, and Applications Marcel Dekker, Inc.: New York, Basel, 2000; p. 16.

(23) Galland, G. B.; de Souza, R. F.; Mauler, R. S.; Nunes, F. F. Macromolecules 1999, 32, $1620-1625$.

(24) Van Berkel, K. Y.; Russell, G. T.; Gilbert, R. G. Polymer 2006, 47, 4667-4675.

(25) Kolthoff, I. M.; Miller, I. K. J. Am. Chem. Soc. 1951, 73, 3055-3059.

(26) Behrman, E. J.; Edwards, J. O. Rev. Inorg. Chem. 1980, 2, 179-206.

(27) Wu, J.; Tomba, J. T.; Oh, J. K.; Winnik, M. A.; Farwaha, R.; Rademacher, J. J. Polym. Sci. Part A 2005, 43, 5581-5596.

(28) German, A. L.; Weerts, P. A.; Gilbert, R. G. Macromolecules 1991, 24, 1622-1682.

(29) Rahman, A.; Brown, C. W. J Appl Polym Sci 1982, 27, 2563-2566.

(30) Monteil, V.; Bastero, A.; Mecking, S. Macromolecules 2005, 38, 5393-5399.

(31) Odian, G. In Principles of Polymerization; John Wiley \& Sons, Inc.: New York, 2004; pp. $350-371$. 
(32) Graillat, C.; Pichot, C.; Guyot, A. Colloids Surf. 1991, 56, 189-200.

(33) Weerts, P. A.; Van der Loos, J. L. M.; German, A. L. Makromol Chem 1991, 192, $1993-$ 2008.

(34) Barham, P. J.; Chivers, R. A.; Keller, A.; Martinez-Salazar, J.; Organ, S. J. J. Mater. Sci. $1985,20,1625-1630$.

(35) Barham, P. J.; Jarvis, D. A.; Keller, A. J. Polym. Sci., Polym. Phys. Ed. 1982, 20, $1733-$ 1748.

(36) Michell, R. M.; Blaszczyk-Lezak, I.; Mijangos, C.; Müller, A. J. Polymer 2013, 54, 40594077.

(37) Hyun, D. C.; Levinson, N. S.; Jeong, U.; Xia, Y. Angew. Chem. Int. Ed. 2014, 53, 37803795.

(38) Steward, P. A.; Hearn, J.; Wilkinson, M. C. Adv. Colloid Interface Sci. 2000, 86, 195267. 


\title{
For Table of Contents use only
}

\section{Free radical emulsion polymerization of ethylene}

\author{
G. Billuart, E. Bourgeat-Lami, M. Lansalot, V. Monteil ${ }^{*}$
}

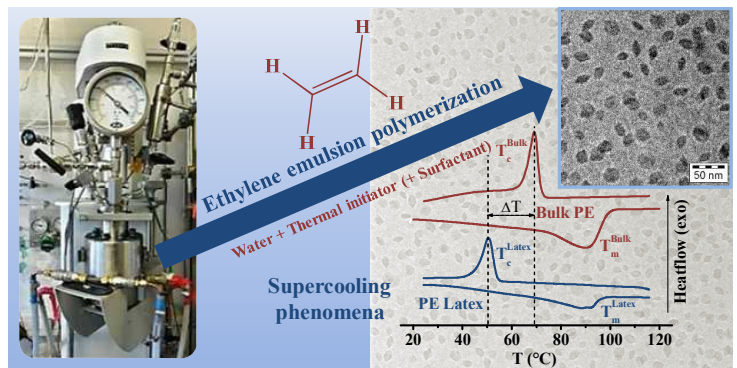

